\title{
Digital Infrastructure, Business Unit Competitiveness, and Firm Performance Growth: The Moderating Effects of Business Unit IT Autonomy
}

\author{
Magno Queiroz \\ Utah State University \\ magno.queiroz@usu.edu
}

\author{
Paul Tallon \\ Loyola University Maryland \\ pptallon@1oyola.edu
}

\author{
Tim Coltman \\ University of Waikato \\ tcoltman@,waikato.ac.nz
}

\author{
Rajeev Sharma \\ University of Waikato \\ rsharma@,waikato.ac.nz
}

\begin{abstract}
This study examines the benefits that firms accrue from digital infrastructures that are effective in supporting corporate and business unit strategic objectives-which we term digital infrastructure effectiveness. We hypothesize that digital infrastructure effectiveness influences two types of performance outcomes-namely, business unit competitive performance and firm performance growth. We further hypothesize that these relationships are both moderated by the degree of business unit IT autonomy. Using data from an international survey of multibusiness firms, we find that business unit IT autonomy exerts differential moderation effects on the relationships between digital infrastructure effectiveness and the two types of performance outcomes. As business unit IT autonomy increases, the effect of digital infrastructure effectiveness on business unit competitive performance gets stronger, while its effect on firm performance growth gets weaker. The primary contribution of this paper is explaining how and when digital infrastructures influence business unit performance and firm performance growth.
\end{abstract}

\section{Introduction}

Digital infrastructure accounts for a large proportion of an organization's investment in IT and provides the foundation for the development of IT capabilities and IT-based business initiatives $[1,2]$. It can lead to improved firm performance, and yet most business executives consider infrastructure investments a "black hole" that eats up resources from more urgent projects such as new applications to support product features [3]. A lack of understanding of infrastructure investments can cause problems in multi-business firms because these firms often rely on digital infrastructures to enable the sharing of IT and data across business units [3-5]. Still, perceptions among business executives that infrastructure investments have limited payoffs is not without some justification, given that infrastructure spending is usually associated with efforts to "keep the lights on" rather than achieving competitive advantage [6]. In line with this view, some studies have argued that infrastructure is becoming a commodity, and therefore it is unlikely to lead to improved performance [7-9].

More recently, seeking to better understand the performance benefits of infrastructure investments, the literature on digital infrastructure has adopted the broader notion of infrastructure as a way of conceptualizing interconnected system collectives rather than hardware components and stand-alone systems $[1,2,10]$. This emerging literature argues that infrastructure investments can produce superior performance gains when the resulting infrastructure components complement and reinforce each other in supporting the organization's strategic objectives [1].

However, the use of enterprise-wide digital infrastructures in multi-business firms can limit the IT autonomy of individual business units [11, 12]. This is a pressing issue for business units - particularly flagship business units that have a significant impact on the firm's bottom line [13] - because lack of IT autonomy can inhibit flexibility and adaptation to market change [14]. In this case, failure in the part of the corporate IT unit in proving an effective digital infrastructure may undermine the business unit's competitive performance (i.e., performance relative to key competitors in a target market) and ultimately affect firm performance growth. Thus, it is natural to expect business units to want total autonomy over its IT portfolios to ensure IT support for core strategic initiatives. At the same time, optimizing performance for the company as a whole may require limiting that autonomy to increase cross-unit coordination [15].

The goal of this study is to extend our understanding of the relationships between digital infrastructure, business unit IT autonomy, and two key types of performance outcomes: business unit competitive performance and firm performance growth. We focus our theory building and theory testing on flagship business units, given their strategic 
importance and contribution to an organization's bottom line. Our theory proposes that corporate-wide and business unit-specific components of a digital infrastructure will generate performance gains when they (1) are effective in supporting corporate and business unit strategic priorities, respectively, and when they (2) complement and reinforce each other.

In developing our theory, we considered the strategic effectiveness of a digital infrastructure as it relates to the firm as a whole and the flagship business unit. $^{1}$ Thus, in this study, digital infrastructure effectiveness concerns two core infrastructure components: corporate-wide IT platform and business unit IT portfolio. Digital infrastructure effectiveness is high when the corporate-wide IT platform is effective in supporting corporate strategic objectives, and the business unit IT portfolio is effective in supporting business unit strategic objectives. We hypothesize that digital infrastructure effectiveness influences business unit competitive performance and firm performance growth. We further hypothesize that these relationships are moderated by business unit IT autonomy.

The proposed theory is tested using data collected from an international survey of multi-business firms. Our results show that digital infrastructure effectiveness enhances both business unit competitive performance and firm performance growth. Moreover, as business unit IT autonomy increases, the positive effect of digital infrastructure effectiveness on business unit competitive performance gets stronger, while its effect on firm performance growth gets weaker. This study contributes to the literature on digital infrastructure by explaining the dual role of digital infrastructure in improving business unit performance and firm performance and by showing how these performance impacts vary as a function of business unit IT autonomy.

\section{Theoretical Background and Hypotheses}

Almost a decade ago, Tilson et al. [10] called for further research on digital infrastructures that underlie digital convergence in organizations and society. They defined an organizational digital infrastructure as the basic information technologies and organizational structures, along with the related services and facilities necessary for the enterprise to function. In their call for research, Tilson et al. [10] argued that as corporate infrastructures become fully digitalized, new generative dynamics emerge that affect the social and technical aspects of infrastructure convergence.

\footnotetext{
${ }^{1}$ Strategic effectiveness concerns the benefits of IT relative to the firm's strategic objectives [4]. For brevity, we hereafter refer to strategic effectiveness as effectiveness.
}

Following this call for research, the literature begun to investigate the generative mechanisms of digital infrastructure evolution [1] and the contradictory tensions that emerge in the infrastructure evolution process [2]. This literature builds on previous studies examining individual infrastructure components such as IT platforms [16, 17], but extends prior treatments of infrastructure by focusing on generative mechanisms such as IT complementarities and integration mechanisms that enable cross-unit coordination [2].

\subsection{Digital Infrastructure Components and Performance Outcomes}

Firms build corporate-wide IT platforms to increase IT standardization and enable global processes [18, 19]. A corporate IT platform refers to the digital IT assets - including hardware, network, applications, and data - that are shared across business units [5, 18]. For example, ABN Amro built a corporate IT platform to better serve its retail, private and commercial banking customers. This platform, based on standardized hardware and software components, allowed $\mathrm{ABN}$ Amro to deploy a worldwide CRM system to record information on all customers (corporate accounts, $\mathrm{SME}$, or retail) down to the level of daily business and profitability. Based on this information, decisions are made to allocate each customer to the business unit manager that is best placed to optimize the profitability of the customer [20]. Individual business units take on the responsibility for cross-selling products and services. At ABN Amro, business units compete based on digitized business solutions (e.g., digitized processes for complex financial transactions) supported by a portfolio of product-related IT applications [21]. Distinguishing between corporate efforts to build corporate IT platforms and business unit efforts to build product-related applications is important because these efforts can be complementary. While corporate IT platforms are coordinated centrally to provide capabilities crossing business unit boundaries - e.g., payroll, channel management, and data sharing -, market-facing business units seek to build a portfolio of IT applications that is product-related and support the IT needs of idiosyncratic activities.

The IT-business alignment literature argues that corporate IT platforms can lead to improved firm performance when the platform is aligned with the corporate strategy [19]. Prior research also argues that developing such platforms can improve performance growth and enable future business opportunities. For example, Quaadgras et al. found that each one of the firms in their study (20 case study sites) "were building 
platforms and 11 had existing platforms that impacted firm performance" [17, p. 116].

Existing literature also argues that individual business units can improve their performance by building IT portfolios that support the business unit strategy $[3,19]$. As business units seek to outmaneuver key competitors and increase competitive performance, they continuously develop and refine product-related IT applications to meet changing business needs. Over time, these efforts become detrimental to improving the effectiveness of local IT applications and enhancing competitive performance [12, 22]. For example, in their study of business units operating in high-tech industries, Roberts and Grover [23] found that those business units with higher levels of analytical ability (i.e., the extent to which IT applications provide analytical tools to support decision making) are better able to gain insight into the data generated by a customer-oriented infrastructure.

\subsection{Digital Infrastructure Effectiveness and Theoretical Perspectives in the Literature}

In their review of the literature on the evolution and impacts of digital infrastructures, Henfridsson and Bygstad [1] identify four research streams outlining distinct theoretical development perspectives in the field:

- Complexity, which focuses on the process by which heterogeneous and autonomous actors seek to use IT in their adaptation to internal and external environments.

- Network, which focuses on the process by which human actors translate and inscribe their interests into a technology, creating a network of human and nonhuman actors.

- Relational, which focuses on the process by which socio-technical relations emerge from IT-mediated activities.

- Strategic asset, which focuses on the process by which managers initiate and implement changes in a firm's portfolio of systems and tools for increasing the alignment between its IT resources and strategic imperatives.

We build on and extend the strategic asset stream of research by considering the effectiveness of two core infrastructure components: the corporate IT platform, whose goal is to support the corporate strategy, and the business unit IT application portfolio, which supports the business unit strategy. The strategic asset perspective suggests that these infrastructure components are effective when they support, or are in alignment with, the firms' strategic objectives [1].
Thus, we define corporate IT platform effectiveness as the extent to which the corporate IT platform supports the corporate strategy. Likewise, business unit IT portfolio effectiveness is defined as the extent to which the business unit IT application portfolio supports the business unit strategy. ${ }^{2}$

The strategic asset perspective builds on strategic choice theory, which argues that achieving performance benefits from digital infrastructure depends not only on the effectiveness of individual infrastructure components but also on transformation mechanisms that allow synergies to emerge from their complementarity [1]. Drawing on this theoretical perspective, we conceptualize digital infrastructure effectiveness as the complementarity between corporate IT platform effectiveness and business unit IT portfolio effectiveness.

Our study contributes to the strategic asset research stream by investigating the performance impacts of digital infrastructure effectiveness. Digital infrastructures are "linked to the need for and ability of organizations to tighten (centralize) and exert control, but also allowing scope for autonomy and loosening of control" [2, p. 648]. Therefore, business unit IT autonomy - meaning the degree to which the business unit is able to meet its IT needs from local sources as opposed to using corporate IT - can shape and constrain the performance effects of digital infrastructure effectiveness. As illustrated in Figure 1, we propose that business unit IT autonomy exerts differential moderation effects on digital infrastructure effectiveness. Next, we develop these ideas and present two hypotheses about the moderation roles of business unit IT autonomy.

\subsection{Impacts of Digital Infrastructure Effectiveness and the Moderating Role of Business Unit IT Autonomy}

Firms usually invest in digital infrastructures in the hope of improving overall firm performance $[1,11]$. However, for individual business units, competitive performance (i.e., performance relative to key competitors) is a more relevant metric because it captures the dynamic outcomes from a business unit's actions to achieve greater competitiveness in its target market segment $[24,25]$. The challenge for these firms is to strike a balance between business unit efforts aimed at improving competitive performance in

\footnotetext{
${ }^{2}$ Corporate strategy is concerned with the set of businesses the firm owns and the management of shared resources. Business unit strategy concerns business-level decisions and the scope of activities under which a business unit operates to build competitive advantage.
} 


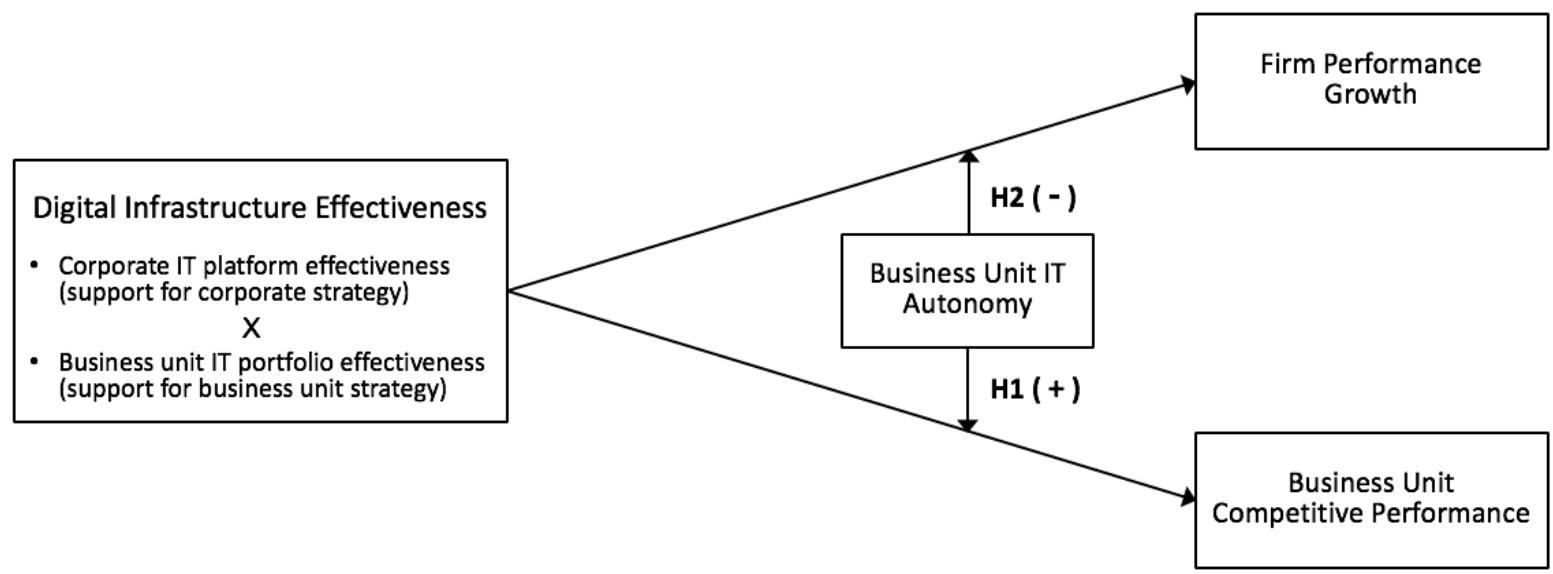

Figure 1. Conceptual model

specific markets and corporate efforts to increase overall performance and enable performance growth.

Conflicts can arise because of trade-offs between centralization and decentralization of IT and the perception among some business units that a decrease in autonomy will hurt their flexibility and performance $[12,14]$. Tilson et al. [10] argued that such conflicts influence the evolution of digital infrastructures and may obscure understanding of IT autonomy in driving infrastructure change. They emphasize that the "opposing logics around centralized and distributed control (or individual autonomy) play ... an important role in the evolution of digital infrastructures" and that "The broad set of affordances that come with IT, however, signify new opportunities for rethinking organizational command and control" (p. 754).

Changes in business unit IT autonomy offers firms such an opportunity to rethink organizational control and influence the type of performance outcomes they can achieve from digital infrastructures. For firms seeking to improve competitive performance in key product markets, an increase in business unit IT autonomy affords individual business units more freedom to leverage the infrastructure and tailor IT solutions to the needs of their market segments [12]. Accordingly, we hypothesize that business unit IT autonomy positively moderates the effect of digital infrastructure effectiveness on business unit competitive performance.

H1: The relationship between digital infrastructure effectiveness and business unit competitive performance is moderated by business unit IT autonomy: the greater the business unit IT autonomy, the stronger the positive effect of digital infrastructure effectiveness on business unit competitive performance.

On the other hand, firms seeking to improve overall performance growth may need to limit business unit IT autonomy [11]. Wu et al. [26] argue that more effective governance practices tend to be centralized because a centralized IT structure can better promote efficient IT use. They also argue that limiting business unit IT autonomy may ease the decision-making process that encapsulates IT-business alignment and improve the role of IT in supporting the corporate strategy, thus facilitating performance growth. Shpilberg et al. [27] make a similar argument to explain why firms often fail to leverage IT for performance growth. They note that "information technology remains a terrible bottleneck to growth in most companies" due, in part, to the fact that firms too often ignore the need for IT standardization and as a result "costs rise, delays mount and the fragmentation makes it difficult for managers to coordinate across business units." (pp. 5152).

Taken together, these arguments suggest that limiting business unit IT autonomy can ease cross-unit coordination, reduce IT fragmentation, and enable effective IT use across the organization, leading to higher firm performance growth. Hence, we propose that business unit IT autonomy negatively moderates the effect of digital infrastructure effectiveness on firm performance growth.

H2: The relationship between digital infrastructure effectiveness and firm performance growth is moderated by business unit IT autonomy: the greater the business unit IT autonomy, the weaker the positive effect of digital infrastructure effectiveness on firm performance growth.

\section{Research Method}

\subsection{Data Collection}

We test our hypotheses using data gathered through a survey of senior IT executives in 120 firms. Our 
sampling frame of 1,200 multi-business organizations (MBOs) includes 800 randomly selected from the U.S. with an additional 400 from Australia and Germany. The survey was administered in 2012, with follow up data collection efforts through 2015 to gather performance data from publicly available data sources.

We identified a corporate CIO familiar with the flagship business unit or, if unknown, the CIO of the business unit as our key informant. A market-facing business unit, also referred to as a strategic business unit (SBU), is defined as an organizational unit that satisfies the following criteria: it resides at the first level of the organizational hierarchy (i.e., immediately below the corporate headquarters); it produces and delivers a distinct set of products or services to a specified external market; and it has profit/loss accountability and distinct operating rules. The average business unit in our sample accounts for $40 \%$ of consolidated corporate revenues.

The participating firms represent a variety of industries, including financial services (19\%), electronics (19\%), manufacturing (17\%), wholesale \& retail trade $(12 \%)$, energy $(11 \%)$, and other industries $(22 \%)$. Overall, $80 \%$ of respondents were corporate CIOs while $20 \%$ were business unit CIOs. Results of a multivariate analysis of variance indicated no significant differences between survey responses from the two groups.

Responses were received from 141 firms, yielding an initial response rate of $12 \%$. Twenty-one responses were excluded due to missing data and so our final response rate is $10 \%$. While low, this is on par with survey response rates noted elsewhere in the IS literature for studies where respondents are senior IT executives [28]. Our assessment of common method bias and non-response bias indicated that these biases do not factor in our study results.

\subsection{Measures}

The survey instrument used in this study is provided in Appendix A. The constructs in our instrument were measured using multiple-item fivepoint Likert scales. The survey was refined using feedback from pilot tests with IT executive sponsors of the MIT Center for Information Systems Research.

To measure corporate IT platform effectiveness, we assess the extent to which the corporate IT platform supports the corporate strategy. Similarly, we assess the extent of business unit IT portfolio effectiveness on the basis of whether the business unit IT application portfolio supports the business unit strategy [19]. In line with prior research that used interaction terms to operationalize complementarity [29], we operationalize digital infrastructure effectiveness as the interaction between corporate IT platform effectiveness and business unit IT portfolio effectiveness.

To measure business unit IT autonomy, we assess the extent to which the IT needs of the business unit are met globally from the corporate IT platform, locally by business unit IT or through a combination of local and global IT. Specifically, we use five items to measure business unit IT autonomy across primary business processes in the value chain: supplier relations, production and operations, product and service enhancement, sales and marketing, and customer relations. These five generic processes span the breadth of the value chain. Business units with high IT autonomy have control over the IT applications needed to execute their core processes. At the other end of the spectrum are business units with low IT autonomy and that are highly dependent on the corporate IT unit to execute their core processes.

Business unit competitive performance was measured using a series of items taken from Powell and Dent-Micallef [30] and Kim et al. [31]. These measures assess market share, revenues, revenue growth, and profitability relative to competitors.

To measure firm performance growth, we collected archival performance data from public sources. ${ }^{3}$ Since a significant portion of the organizational impacts of IT is accounted for by IT-enabled revenue growth [32], we collected archival data on firm revenues for 2012 (the year of the survey) and for the following year. The collected data allowed us to calculate the 2013 revenue growth rate (i.e., growth rate lagged one year). In addition, we collected return on assets (ROA) data for the same period and calculated ROA growth rate. We used this measure to perform robustness tests and triangulate our findings.

Control variables were used to account for differences in firm ownership structure (public/private), business unit contribution to firm revenue (percentage of total revenue), business unit size, business unit strategic orientation, and industry type. To assess strategic orientation, we used a measure taken from Tallon [33] that distinguishes between business units pursuing operational excellence and those pursuing differentiation.

\subsection{Data Analysis}

We performed a regression-based analysis of conditional effects to test our hypotheses [34]. This approach implements an ordinary least squares regression-based procedure based on bootstrapped

\footnotetext{
${ }^{3}$ We collected these data for a total of 69 firms. The remaining firms in our sample are private or were anonymized by respondents under the rules set by our IRB for collecting survey data.
} 
Table 1. Validity and reliability statistics and correlations between constructs

\begin{tabular}{lccccccc}
\hline Research Constructs & CR & AVE & $\mathbf{1}$ & $\mathbf{2}$ & $\mathbf{3}$ & $\mathbf{4}$ & $\mathbf{5}$ \\
\hline 1. Corporate IT platform effectiveness & 0.81 & 0.55 & $\mathbf{0 . 7 6}$ & & & & \\
2. Business unit IT portfolio effectiveness & 0.82 & 0.55 & 0.63 & $\mathbf{0 . 7 4}$ & & & \\
3. Business unit IT autonomy & 0.92 & 0.71 & -0.39 & -0.34 & $\mathbf{0 . 7 1}$ & & \\
4. Business unit competitive performance & 0.91 & 0.66 & 0.26 & 0.25 & -0.22 & $\mathbf{0 . 8 2}$ & \\
5. Firm performance growth & n.a & n.a & 0.16 & 0.23 & -0.10 & 0.26 & n.a \\
\hline
\end{tabular}

Notes: $\mathrm{CR}=$ Composite Reliability; The bold numbers on the diagonal are the square root of the AVE; Off-diagonal

elements are correlations between each pair of constructs.

estimates and can be used to compute $p$ values and confidence intervals for direct, indirect, and moderation effects [34, 35]. We performed this analysis using the PROCESS macro in IBM SPSS statistics $[34,35]$. We averaged the items in each scale to form scale scores [36]. In addition, we mean centered the measures used in interaction terms.

\section{Research Results}

\subsection{Measurement Model Assessment}

To test our measurement model, we performed an exploratory analysis of the underlying questionnaire items. All construct-to-item loadings are significant and the items load more highly on their own constructs than on others. Construct correlations, composite reliability, and average variance extracted (AVE) are summarized in Table 1.

To assess internal consistency, we examined composite reliability. Composite reliability for each construct exceeds 0.81 . In order to assess discriminant validity, we examined AVE and correlations among our constructs. The diagonal elements in Table 1 represent the square root of AVE and exceed the offdiagonal elements in the correlation matrix.

Multicollinearity among constructs is also an important validity concern, particularly in studies examining complementarity because the components of a complementary relationship co-vary and are expected to correlate. To address this issue, we performed a series of collinearity tests. These tests reveal minimal collinearity with all variance inflation factors (VIF) below 2.2. Together, these results suggest that our measures are valid and reliable.

\subsection{Hypotheses Testing}

The results of our analysis are presented in Table 2 . The results for $\mathrm{H} 1$ in Table 2 (model 1) find that business unit IT autonomy positively moderates the effect of digital infrastructure effectiveness on business unit competitive performance $(\beta=0.194 ; p<0.05)$. As business unit IT autonomy increases, the positive effects of digital infrastructure effectiveness on business unit competitive performance get stronger. Thus, H1 is supported. In Figure 2, we depict the Johnson-Neyman region of significance for digital infrastructure effectiveness, showing how its effect on performance changes as a function of business unit IT autonomy to the point where it becomes significant (i.e., the $95 \% \mathrm{CI}$ does not include zero).

Interestingly, we also find that as business unit IT autonomy increases, the effect of business unit IT portfolio effectiveness on business unit competitive performance weakens $(\beta=-0.229 ; p<0.001)$. Together with the pattern of relationship outlined in Figure 2, this finding suggests that there is a degree of substitution between broader digital infrastructures and business unit-specific IT portfolios. As IT autonomy increases, business units will be better able to partner with the corporate IT unit and leverage corporate-wide digital infrastructure capabilities. In this case, local business unit IT portfolios are no longer the single source of IT support for business units and, although they remain key enablers of business unit competitive performance, their performance effects will diminish.

In the case of $\mathrm{H} 2$, the results in Table 2 (model 2) find that business unit IT autonomy negatively moderates the effect of digital infrastructure effectiveness on firm performance growth $(\beta=-0.419$; $p<0.01)$. As business unit IT autonomy increases, the effects of digital infrastructure effectiveness on firm performance growth get weaker. $\mathrm{H} 2$ is therefore supported. Figure 3 depicts the Johnson-Neyman region of significance for this relationship.

As a robustness test, we reevaluated $\mathrm{H} 2$ using ROA growth rate as our measure of firm performance growth. Specifically, we reestimated model 2 in Table 2 using ROA growth rate. The results of this analysis are all consistent with our findings above. As expected, we find that business unit IT autonomy negatively moderates the effect of digital infrastructure effectiveness on ROA growth rate $(\beta=-0.402 ; p<$ $0.01)$. These findings provide further support for $\mathrm{H} 2$. 
Table 2. Results of conditional effects analysis

\begin{tabular}{|c|c|c|c|c|}
\hline & \multicolumn{2}{|c|}{$\begin{array}{l}\text { Model 1: } \\
\text { Business Unit Competitive } \\
\text { Performance }(\mathrm{N}=120)\end{array}$} & \multicolumn{2}{|c|}{$\begin{array}{l}\text { Model 2: } \\
\text { Firm Performance Growth } \\
(\mathrm{N}=69)\end{array}$} \\
\hline & Coeff. & $95 \% C I$ & Coeff. & $95 \% C I$ \\
\hline Size & 0.080 & {$[-0.0154,0.1756]$} & 0.100 & {$[-0.0772,0.2788]$} \\
\hline Contribution to revenue & 0.002 & {$[-0.0043,0.0075]$} & $0.011^{*}$ & {$[0.0006,0.0211]$} \\
\hline Strategic orientation ${ }^{\text {a }}$ & 0.196 & {$[-0.1047,0.4985]$} & 0.231 & {$[-0.2919,0.7550]$} \\
\hline Ownership structure ${ }^{a}$ & 0.095 & {$[-0.2248,0.4143]$} & 0.401 & {$[-0.6054,1.4048]$} \\
\hline Industry type ${ }^{a}$ & Included & & Included & \\
\hline Digital infrastructure effectiveness & -0.143 & {$[-0.3997,0.1135]$} & $0.834 * *$ & {$[0.3152,1.3528]$} \\
\hline Corporate platform effectiveness & 0.085 & {$[-0.1451,0.3165]$} & 0.082 & {$[-0.3065,0.4704]$} \\
\hline Business unit IT portfolio effectiveness & $0.314 *$ & {$[0.0605,0.5681]$} & 0.120 & {$[-0.3230,0.5648]$} \\
\hline Business unit IT autonomy & $-0.156^{\dagger}$ & {$[-0.3125,0.0005]$} & 0.130 & {$[-0.1411,0.4025]$} \\
\hline $\begin{array}{l}\text { Corporate platform effectiveness } \mathrm{x} \\
\text { Business unit IT autonomy }\end{array}$ & 0.078 & {$[-0.1313,0.2891]$} & 0.2059 & {$[-0.1208,0.5326]$} \\
\hline $\begin{array}{l}\text { Business unit IT portfolio effectiveness } \\
\text { x Business unit IT autonomy }\end{array}$ & $-0.299 * *$ & {$[-0.5146,-0.0838]$} & -0.294 & {$[-0.6531,0.0643]$} \\
\hline $\begin{array}{l}\text { Digital infrastructure effectiveness } x \\
\text { Business unit IT autonomy }\end{array}$ & $0.194 *$ & {$[0.0379,0.3511]$} & $-0.419 * *$ & {$[-0.6847,-0.1539]$} \\
\hline $\mathrm{R}^{2}$ & 0.2839 & & 0.3656 & \\
\hline
\end{tabular}

\section{Discussion}

This study was motivated by the increasingly strategic role of digital infrastructures and the limited understanding of the conditions under which they lead to business unit competitive performance and firm performance growth. We propose and test a theory of the differential moderation effects of business unit IT autonomy on digital infrastructure effectiveness.

\subsection{Implications for Research}

In developing our theory, we introduced a new construct, namely digital infrastructure effectiveness, to assess synergies that arise from complementarities between corporate-wide and business unit-specific infrastructure components. Prior research argues that digital infrastructure can lead to improved firm performance [1]. We extend this body of literature by explaining how distinct infrastructure components interact with each other, and when -i.e., the conditions under which - the resulting digital infrastructure matters most for business unit competitive performance and for firm performance growth.
Noteworthy in our theory is the differential moderating roles of business unit IT autonomy. Tests of the proposed ideas have two substantive theoretical implications for the digital infrastructure literature. First, the amount of value firms can derive from digital infrastructures depends on corporate-business unit interactions and whether collaborative efforts to build and extend the infrastructure supports both corporatelevel and business unit-level strategic objectives [3, 19]. Second, firms employing a highly centralized IT structure that limits local business unit IT autonomy are less likely to see improvements in business unit competitive performance from infrastructure investments. Likewise, firms employing a highly decentralized IT structure that limits IT standardization and cross-unit IT synergies are less likely to see improvements in firm performance growth from their infrastructure investments [11].

\subsection{Implications for Practice}

More knowledge about the performance impacts of digital infrastructure is valuable for IT executives seeking to improve infrastructure effectiveness and 


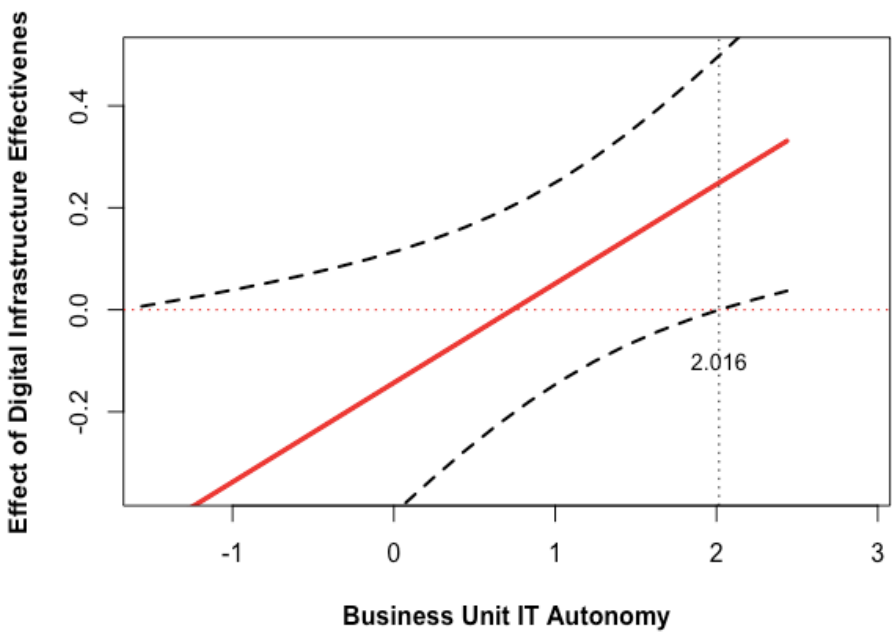

$95 \%$ ULCI

Point estimate

$95 \%$ LLCI

Figure 2. Region of significance: effect of digital infrastructure effectiveness on business unit competitive performance

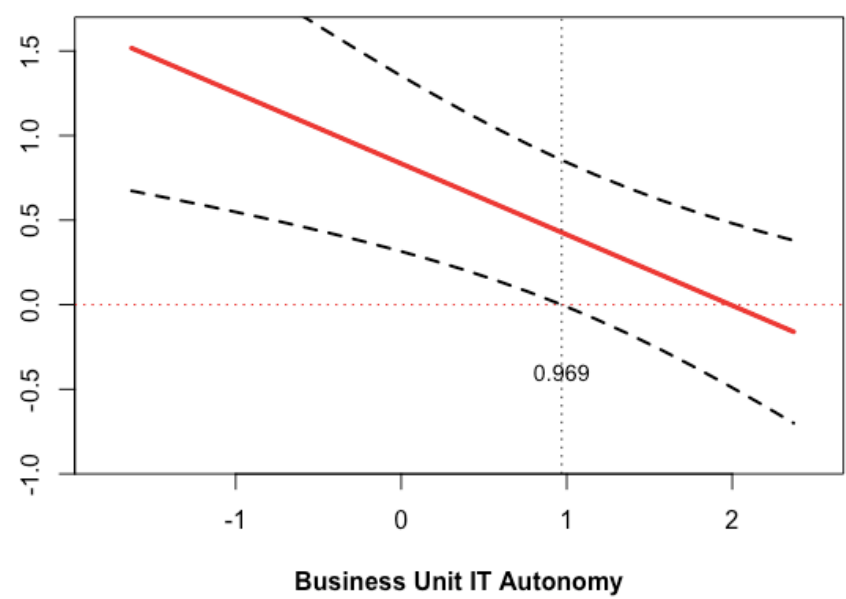

$95 \%$ ULCI

Point estimate

Figure 3. Region of significance: effect of digital infrastructure effectiveness on firm performance growth

manage tensions between corporate parents and business units. Our study points to the critical role of business unit IT autonomy as a valuable mechanism that can be used by managers to shift the focus of digital infrastructure investments and potentialize desired outcomes. Specifically, when business unit competitive performance is the priority, managers should seek to increase business unit IT autonomy and incentivize the development of idiosyncratic IT applications to support business unit time-to-market [12]. On the other hand, firms seeking to increase overall firm performance and enable sustainable firm performance growth should limit local IT autonomy in order to increase IT standardization across the organization and achieve cross-unit IT synergy [27].

\section{Conclusion}

Our theory of digital infrastructure effectiveness begins to shift attention from examinations of whether digital infrastructure matters toward more multifaceted assessments of the conditions under which they matter most and to whom. As firms invest in digital infrastructures, IT managers' ability to translate these investments into performance gains for individual business units and for the firm as a whole is increasingly dependent on the coordination of corporate and business unit actions and managing business unit expectations regarding the trade-offs of increased business unit IT autonomy.

\section{References}


[1] O. Henfridsson and B. Bygstad, "The generative mechanisms of digital infrastructure evolution", MIS Quarterly, 37 (2013), pp. 907-931.

[2] R. Montealegre, K. Iyengar and J. Sweeney, "Understanding Ambidexterity: Managing Contradictory Tensions Between Exploration and Exploitation in the Evolution of Digital Infrastructure", Journal of the Association for Information Systems, 20 (2019), pp. 647680.

[3] N. Fonstad and M. Subramani, "Building Enterprise Alignment: A Case Study", MIS Quarterly Executive, 8 (2009), pp. 31-41.

[4] J. W. Ross, "Generating Strategic Benefits from Enterprise Architecture", MIT CISR Research Briefing, IV (2004), pp. 1-4.

[5] J. Ross, P. Weill and D. Robertson, Enterprise Architecture as Strategy: Creating a Foundation for Business Execution, Harvard Business School Press, Boston, MA, 2006.

[6] N. G. Carr, "IT Doesn't Matter", Harvard Business Review, 81 (2003), pp. 41-49.

[7] S. Dong, S. X. Xu and K. X. Zhu, "Research noteInformation Technology in Supply Chains: The Value of ITenabled Resources under Competition", Information Systems Research, 20 (2009), pp. 18-32.

[8] G. D. Bhatt and V. Grover, "Types of information technology capabilities and their role in competitive advantage: an empirical study", Journal of Management Information Systems, 22 (2005), pp. 253-277.

[9] D. Goodhue, B. Wixom and H. Watson, "Realizing business benefits through CRM: hitting the right target in the right way", MIS Quarterly Executive, 1 (2002), pp. 79-94.

[10] D. Tilson, K. Lyytinen and C. Sørensen, "Research commentary-Digital infrastructures: The missing IS research agenda", Information Systems Research, 21 (2010), pp. $748-759$.

[11] H. Tanriverdi, "Performance Effects of Information Technology Synergies in Multibusiness Firms", MIS Quarterly, 30 (2006), pp. 57-77.

[12] J. W. Ross and C. M. Beath, Agility and Risk Management at Pacific Life: Optimizing Business Unit Autonomy, MIT CISR Working Paper WP 372, Cambridge, MA: MIT Press, 2007, pp. 1-13.

[13] V. Gaba and J. Joseph, "Corporate Structure and Performance Feedback: Aspirations and Adaptation in Mform Firms", Organization Science, 24 (2013), pp. 11021119 .
[14] P. Tallon, M. Queiroz, T. Coltman and R. Sharma, "Information Technology and the Search for Organizational Agility: A Systematic Review with Future Research Possibilities", The Journal of Strategic Information Systems, 28 (2019), pp. 218-237.

[15] P. Puranam, H. Singh and M. Zollo, "Organizing for innovation: Managing the coordination-autonomy dilemma in technology acquisitions", Academy of Management Journal, 49 (2006), pp. 263-280.

[16] M. Broadbent, P. Weill and D. St. Clair, "The Implications of Information Technology Infrastructure for Business Process Redesign", MIS Quarterly, 23 (1999), pp. 159-182.

[17] A. Quaadgras, P. Weill and J. W. Ross, "Management commitments that maximize business impact from IT", Journal of Information Technology, 29 (2014), pp. 114-127.

[18] R. G. Fichman, "Real Options and IT Platform Adoption: Implications for Theory and Practice", Information Systems Research, 15 (2004), pp. 132-154.

[19] P. Reynolds and P. Yetton, "Aligning Business and IT Strategies in Multi-Business Organizations", Journal of Information Technology, 30 (2015), pp. 101-118.

[20] J. Strikwerda and J. Stoelhorst, "The Emergence and Evolution of the Multidimensional Organization", California Management Review, 51 (2009), pp. 11-31.

[21] V. Sambamurthy and R. Zmud, Business Platforms, Digital Platforms and Digital Innovation: An Executive Agenda, Legerity Digital Press, LLC, 2015.

[22] P. Weill and J. Ross, "A Matrixed Approach to Designing IT Governance", MIT Sloan Management Review, 46 (2005), pp. 26-34

[23] N. Roberts and V. Grover, "Leveraging Information Technology Infrastructure to Facilitate a Firm's Customer Agility and Competitive Activity: An Empirical Investigation", Journal of Management Information Systems, 28 (2012), pp. 231-270.

[24] A. Rai and X. Tang, "Leveraging IT capabilities and competitive process capabilities for the management of interorganizational relationship portfolios", Information Systems Research, 21 (2010), pp. 516-542.

[25] W. J. Ferrier, "Navigating the competitive landscape: The drivers and consequences of competitive aggressiveness", Academy of Management Journal, 44 (2001), pp. 858-877.

[26] S. Wu, D. Straub and T.-P. Liang, "How Information Technology Governance Mechanisms and Strategic Alignment Influence Organizational Performance: Insights 
from a Matched Survey Of Business and IT Managers", MIS Quarterly, 39 (2015), pp. 497-518.

[27] D. Shpilberg, S. Berez, R. Puryear and S. Shah, "Avoiding the Alignment Trap in Information Technology", MIT Sloan Management Review, 49 (2007), pp. 51-58.

[28] J. E. Gerow, J. B. Thatcher and V. Grover, "Six Types of IT-Business Strategic Alignment: An Investigation of the Constructs and Their Measurement", European Journal of Information Systems, 24 (2015), pp. 465-491.

[29] M. Song, C. Droge, S. Hanvanich and R. Calantone, "Marketing and Technology Resource Complementarity: An Analysis of Their Interaction Effect in Two Environmental Contexts", Strategic Management Journal, 26 (2005), pp. 259-276.

[30] T. C. Powell and A. Dent-Micallef, "Information Technology as Competitive Advantage: The Role of Human, Business, and Technology Resources", Strategic Management Journal, 18 (1997), pp. 375-405.

[31] G. Kim, B. Shin, K. K. Kim and H. G. Lee, "IT Capabilities, Process-Oriented Dynamic Capabilities, and Firm Financial Performance", Journal of the Association for Information Systems, 12 (2011), pp. 487-517.

[32] S. Mithas, A. R. Tafti, I. R. Bardhan and J. M. Goh, "Information Technology and Firm Profitability: Mechanisms and Empirical Evidence", MIS Quarterly, 36 (2012), pp. 205-224.

[33] P. P. Tallon, "A Process-oriented Perspective on the Alignment of Information Technology and Business Strategy", Journal of Management Information Systems, 24 (2008), pp. 227-268.

[34] A. F. Hayes, Introduction to Mediation, Moderation, and Conditional Process Analysis: A Regression-based Approach, Guilford Press, New York, NY, 2017.

[35] G. J. Kilduff, A. D. Galinsky, E. Gallo and J. J. Reade, "Whatever it takes to win: Rivalry increases unethical behavior", Academy of Management Journal, 59 (2016), pp. 1508-1534.

[36] Y. Lu and K. Ramamurthy, "Understanding the Link Between Information Technology Capability and Organizational Agility: An Empirical Examination", MIS Quarterly, 35 (2011), pp. 931-954.

\section{Appendix A. Survey Items}

Corporate IT Platform Effectiveness (1: Strongly

disagree; 5: Strongly agree)

To what extent do the following statements reflect the current situation in the $M B O$ ? a. The corporate IT platform lacks capabilities that are necessary to enable the effective execution of the corporate strategy.

b. The organization is a long way short of where the corporate IT platform capabilities need to be to support the corporate strategy.

c. The potential of the corporate IT platform is not fully considered when corporate strategy decisions are made.

d. Overall, the corporate IT platform meets the needs of the corporate strategy.

Business Unit IT Portfolio Effectiveness (1: Strongly disagree; 5: Strongly agree)

To what extent do the following statements reflect the current situation in the SBU?

a. The existing SBU IT application portfolio lacks capabilities that are necessary to effectively execute the SBU strategy.

b. The existing SBU IT application portfolio provides sufficient support for the execution of our SBU strategy.

c. The potential of the SBU IT application portfolio is not fully considered when SBU strategy decisions are made.

d. Overall, the SBU IT application portfolio meets the needs of the SBU strategy.

Business Unit IT Autonomy (1: Corporate IT platform only; 3: Equally by SBU \& corporate IT platform; 5: SBU only)

Please indicate the sources of IT application support for the following business processes.

a. Supplier relations.

b. Product/service operations.

c. Product/service enhancement.

d. Sales and marketing.

e. Customer relations.

Business Unit Competitive Performance (1: Strongly disagree; 5: Strongly agree)

Adapted fromand Dent-Micallef [30] and Kim et al [31].

To what extent do the following statements reflect the current situation in the SBU?

a. We are more profitable than our competitors.

b. Our sales growth exceeds that of our competitors.

c. Our revenue growth exceeds that of our competitors.

d. Our market share growth exceeds that of our competitors.

e. Overall, our performance is better than our competitors. 